\section{The variability of materiality in financial reporting: in defense of the pretense}

Variability of materiality

Dedicated to the memory of George Christian Holdren 1924-2015

T'was nigh 40 years ago that the dominance of quantitative criteria By far overshadowed the materiality of qualitative criteria And calls for considering the nature of a disclosure Focused on whether an item was critical in the eyes of the userThere was a judgment decision required

T'was nigh 30 years ago that in deciding whether an item is material Its nature and its amount would both be taken into account And be evaluated together to present fairly the annual accountsThere was a judgment decision required

T'was nigh 20 years ago that it was proposed to disclose materiality thresholds To reveal the extent to which the auditor has planned and performed the audit To reasonably detect the occurrence of a material fraud and error strangleholdThere was a judgment decision required

T'was nigh 17 years ago that the SEC promulgation on materiality

Stated that percentage terms are only the beginning of an analysis of materiality And cannot be used as a substitute for full materiality

And considered it a transgression if there was a qualitative omission-

There was a judgment decision required

The search for guidance on implementation of materiality decisions

Goes on as financial reporting lapses continue to lead to indecision

The question is will a practice set change the dominant quantitative mindset?-

Still a judgment decision is required

Ashley Burrowes

Mittuniversitetet, Sundsvall, Sweden, and

John E. Karayan

University of Southern California, Los Angeles, California, USA

With thanks to Professor Lloyd Sage for incisive interactions. 